\title{
Etiologia da mortalidade de miniestacas de Eucalyptus benthamii e possíveis fontes de inóculo
}

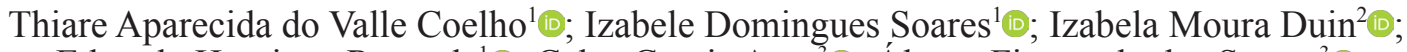

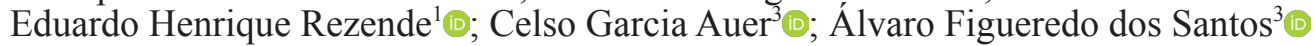

\begin{abstract}
${ }^{1}$ Programa de Pós-graduação em Engenharia Florestal, Universidade Federal do Paraná, Curitiba, PR, Brasil. ${ }^{2}$ Instituto Agronômico do Paraná IAPAR, Londrina, PR, Brasil. ${ }^{3}$ Embrapa Florestas, CP 319, 83411-000, Colombo, PR, Brasil.

Autor para correspondência. Celso Garcia Auer (celso.auer@embrapa.br).

Data de chegada: 19/02/2018 Data de aceite: 14/10/2018
\end{abstract}

$10.1590 / 0100-5405 / 191788$

\section{RESUMO}

Coelho, T.A.V.; Soares, I.D.; Duin, I.M.; Rezende, E.H.; Auer, C.G.; Santos, A.F. dos. Etiologia da mortalidade de miniestacas de Eucalyptus benthamii Maiden et Cambage e possíveis fontes de inóculo. Summa Phytopathologica, v.45, n.2, p.157-163, 2019.

Eucalyptus benthamii é originário da Austrália, cultivado na região Sul do Brasil, devido à sua tolerância ao clima frio. Durante a produção de mudas dessa espécie vários fatores bióticos e abióticos adversos têm surgido em viveiros. Dessa forma, o presente trabalho teve como objetivo avaliar a podridão de miniestacas de E. benthamii em três clones comerciais, a patogenicidade dos principais fungos encontrados e as principais fontes de inóculo dos fungos causadores dessa doença. As coletas foram realizadas em viveiro clonal de Guarapuava/PR, em setembro de 2016 ( $1^{\text {a }}$ coleta) e abril de 2017 ( $2^{\mathrm{a}}$ coleta). Coletaram-se miniestacas em fase de enraizamento com sintomas de podridão aparente, brotações sadias, amostras do substrato utilizado para o enraizamento, areia proveniente do minijardim clonal, tubetes, e britas provenientes do piso da estufa. Para deteç̧ão e identificação dos fungos, utilizaram-se os métodos de isolamento direto, isolamento indireto, diluição em série, teste com isca de folha de mamona (Ricinus communis) e plaqueamento de resíduos. Botrytis cinerea, Complexo Calonectria scoparia, Fusarium spp. e Pestalotiopsis sp. são os agentes causais da podridão de miniestacas em E. benthamii. Miniestaca assintomática, tubete plástico reutilizado, brita, areia e substrato reutilizado podem ser as principais fontes de inóculo.

Palavras-chave: Botrytis cinerea, Complexo Calonectria scoparia, doenças em viveiro, eucalipto.

\section{ABSTRACT}

Coelho, T.A.V.; Duin, I.M.; Rezende, E.H.; Auer, C.G.; Santos, A.F. dos. Etiology of the mortality of Eucalyptus benthamii minicuttings and possible inoculum sources. Summa Phytopathologica, v.45, n.2, p.157-163, 2019.

Eucalyptus benthamii is native to Australia and cultivated in the Southern region of Brazil due to its tolerance to the cold climate. During seedling production, several biotic and abiotic adverse factors have arisen in nurseries. Thus, the present study aimed to evaluate rot of E. benthamii minicuttings in three commercial clones, as well as the pathogenicity of the main found fungi and the major inoculum sources of the fungi that cause this disease. Samples were collected from a clonal nursery at Guarapuava/PR, in September 2016 ( $1^{\text {st }}$ collection $)$ and April 2017 ( $2^{\text {nd }}$ collection $)$. Minicuttings with rot symptoms during rooting, healthy shoots, samples of the substrate used for rooting, sand of clonal mini garden, reused plastic tubes, and brittle from the greenhouse floor were collected. The methods of direct isolation, indirect isolation, serial dilution, castor bean (Ricinus communis) bait test and residue plating were used for detection and identification of the fungi. Botrytis cinerea, Calonectria scoparia complex, Fusarium spp. and Pestalotiopsis sp. are the causal agents of rot in E. benthamii minicuttings. Asymptomatic minicutting, reused plastic tube, brittle, sand and reused substrate can be the main inoculum sources.

Keywords: Botrytis cinerea, Calonectria scoparia complex, nursery diseases, eucalypt.

Eucalyptus benthamii Maiden et Cambage é originário da Austrália, ao oeste da cidade de Sydney em planícies ao longo do rio Nepean (9). A espécie foi introduzida no Brasil, em 1910, por Navarro de Andrade, mas mostrou pouca importância em plantios experimentais no estado de São Paulo (12). A partir de novos ensaios conduzidos no final da década de 1980, verificou-se potencial para plantios comerciais em áreas com ocorrências de geadas no Brasil (13). Segundo Schultz (17), em 2011 haviam cerca de 10.000 ha com plantios puros de $E$. benthamii na região Sul. Assim, existe uma demanda constante por mudas dessa espécie e vários fatores bióticos e abióticos adversos foram detectados durante a produção de mudas em viveiros (17).

Viveiros florestais apresentam características propícias para a ação de organismos fitopatogênicos como: alta umidade relativa do ar, temperaturas amenas a elevadas, tecido vegetal tenro, proximidade entre mudas e cultivo contínuo da mesma espécie. Nos viveiros, as doenças podem ocorrer tanto nos jardins e minijardins clonais, como durante seu crescimento e rustificação, ocasionando prejuízos significativos (2).

Desta forma, os objetivos desse trabalho foram avaliar a podridão de miniestacas de $E$. benthamii em três clones em um viveiro comercial, testar a patogenicidade dos principais fungos encontrados e buscar as fontes de inóculo dos fungos associados.

\section{MATERIAL E MÉTODOS}

Amostragem da podridão de miniestacas e fontes de inóculo no viveiro

Miniestacas com sintomas caracterizados por podridão basal ou 
podridão mediana foram coletadas no viveiro (Figura 1). As coletas foram realizadas em duas épocas distintas: setembro de $2016\left(1^{\mathrm{a}}\right.$ coleta) e abril de 2017 ( $2^{\text {a }}$ coleta), em Guarapuava/PR, de três clones comerciais: B1, B2 e B3. Para avaliar a podridão de miniestacas, foram coletadas 150 miniestacas por clone por coleta.

Para a coleta, a estufa foi percorrida arbitrariamente, retirando-se miniestacas doentes, as quais foram embaladas em sacos plásticos limpos, identificadas e levadas para análise no laboratório (1).

\section{Isolamento do material doente}

Foram utilizados os métodos de isolamento direto (incubação em câmara úmida com iluminação ambiente até a formação de estruturas reprodutivas que possibilitassem a identificação - 7 a 14 dias) e isolamento indireto que consistiu na retirada de fragmentos de tecido da região limítrofe entre o tecido sadio e o doente e sua posterior desinfestação (álcool $70 \%$ por $30 \mathrm{~s}, \mathrm{NaClO} 1 \%$ por 1 min), plaqueamento em placas de Petri com meio batata-dextrose-ágar (BDA), incubação em câmara B.O.D, a $24 \pm 2{ }^{\circ} \mathrm{C}$, no escuro até a formação de colônias (1). Os isolados foram agrupados em morfotipos para posterior identificação.

\section{Identificação dos fungos isolados}

A identificação foi realizada em culturas puras, obtidas pela repicagem de fragmentos de micélio-ágar para novas placas com meio BDA, incubadas em câmara B.O.D, a $24 \pm 2{ }^{\circ} \mathrm{C}$, no escuro. Lâminas semipermanentes foram preparadas com estruturas reprodutivas, coradas com solução de Amann (10). Através da observação microscópica das lâminas em microscópio ótico, em aumentos de 100x e 450x, foi feita a identificação, ao nível de gênero, utilizando as descrições de Barnett $\&$ Hunter (5). Os isolados foram preservados pelo método de Castellani e depositados na Coleção de Fungos e Oomicetos Florestais do Lab. de Patologia Florestal da Embrapa Florestas, Colombo, PR.

\section{Teste de patogenicidade}

A patogenicidade foi avaliada com os isolados dos fungos que apresentaram maior incidência em associação com a podridão de miniestacas de $E$. benthamii e descritos na literatura como patógenos. Foram testados um isolado de Botrytis cinerea Pers., isolados 1, 2 e 3 Complexo Cs, isolados 1 e 2 de Fusarium sp. e um de Pestalotiopsis sp.

Dez miniestacas de cada clone (B1, B2 e B3) foram usadas para cada isolado mais dez para a testemunha. As miniestacas apresentavam cerca de dez cm de comprimento e, para melhor disposição, suas folhas foram cortadas ao meio. As miniestacas foram desinfestadas superficialmente com álcool $70 \%$ por $30 \mathrm{~s} \mathrm{e} \mathrm{NaClO} 1 \%$ por $1 \mathrm{~min}$, seguido de lavagem com água ultrapurificada estéril, e deixadas sobre papel mata-borrão esterilizado para retirar o excesso de água. Discos de micélio-ágar de sete $\mathrm{mm}$ de diâmetro foram retirados de culturas em meio BDA, inoculados nas bases das miniestacas sadias (8). Como testemunha, as miniestacas foram inoculadas com discos de meio BDA.

As miniestacas inoculadas foram incubadas em caixas gerbox com papel mata-borrão estéril umedecido, mantidas sob luz fluorescente contínua, em câmara B.O.D à temperatura $24 \pm 2{ }^{\circ} \mathrm{C}$, por 14 dias. As avaliações ocorreram aos sete e 14 dias após a inoculação, verificandose a presença de sintomas, e medindo-se comprimento das lesões com paquímetro digital. O reisolamento consistiu no isolamento indireto dos fragmentos com sintomas de cada miniestaca em meio BDA, seguindo metodologia citada anteriormente e incubados em câmara B.O.D a 24 $\pm 2{ }^{\circ} \mathrm{C}$, e fotoperíodo de $12 \mathrm{~h}$.

Os dados de patogenicidade foram submetidos ao teste de homogeneidade de variâncias de Bartlett, análise de variância (ANOVA)

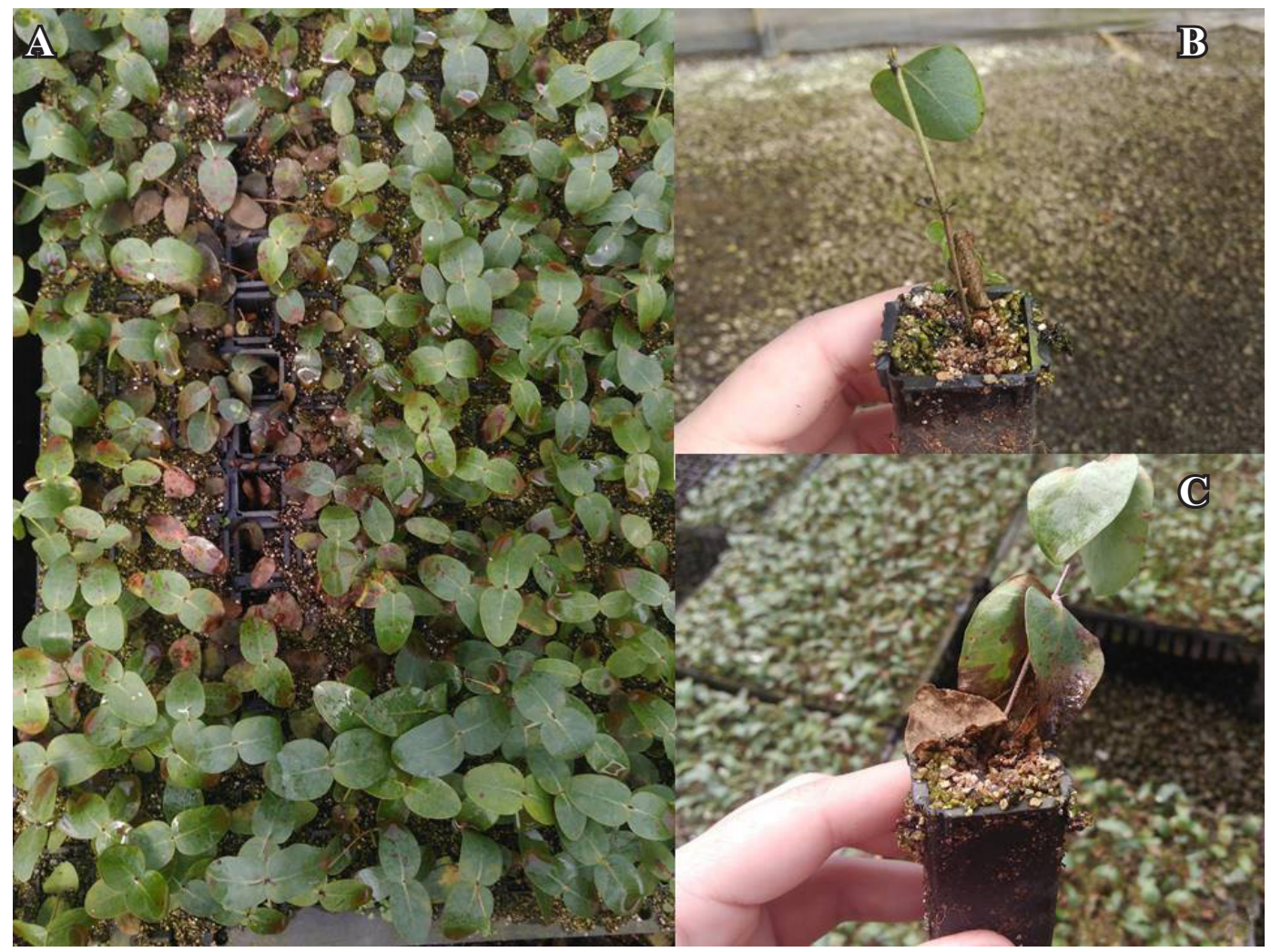

Figura 1. Mortalidade de miniestacas de Eucalyptus benthamii em casa de vegetação. A: Mortalidade de miniestacas em reboleira; B - C: Miniestacas apresentando podridão na base. 
e compararam-se as médias pelo teste de Tukey a $5 \%$, por meio do programa ASSISTAT (18).

\section{Avaliação de fontes de inóculo de patógenos}

Miniestacas assintomáticas dos minijardins clonais, amostras de substrato novo e usado, areia proveniente dos canaletões dos minijardins clonais, tubetes plásticos e britas provenientes da estufa foram coletadas para análise de fontes de inóculo. As amostras foram embaladas em sacos plásticos limpos, lacrados, identificadas e mantidas sob refrigeração a $6{ }^{\circ} \mathrm{C}$, antes do processamento. $\mathrm{O}$ procedimento para coleta e de isolamento foi diferente para cada tipo de material.

Para miniestaca assintomática, coletou-se arbitrariamente 50 brotações de cada clone, e fez-se isolamento direto em câmara úmida.

Tubetes plásticos usados que apresentaram miniestacas com sintomas de podridão basal ou podridão mediana foram coletados no interior da estufa. A partir destes tubetes, separaram-se as miniestacas doentes e o substrato usado e contaminado. Também, foram coletados tubetes plásticos usados e lavados com jato de água. Foi utilizada a metodologia utilizada por Duin et al. (8), que consistiu na lavagem dos tubetes em copo de Béquer esterilizado por autoclavagem com $20 \mathrm{~mL}$ de água estéril, com auxílio de uma escova previamente esterilizada por 1 min em $\mathrm{NaClO} 1 \%$ e enxaguada em água esterilizada. A partir da solução da lavagem, foram coletadas, com micropipeta, alíquotas de $10 \mu \mathrm{L}, 50 \mu \mathrm{L}$, e $100 \mu \mathrm{L}$ da solução e espalhadas em placas de Petri contendo meio de Martin. Cada diluição teve três repetições, sendo as placas incubadas conforme descrito para o isolamento de fungos provenientes do substrato.

No caso de substratos, o substrato novo foi coletado diretamente de embalagens ainda fechadas, onde se retiraram três amostras. $\mathrm{O}$ substrato usado e contaminado foi o mesmo retirado diretamente dos tubetes usados, do qual foram coletadas três amostras. Para o isolamento, foi utilizada a técnica de diluição em série descrita por Mello et. al. (11). Diluíram-se $10 \mathrm{~g}$ de substrato em $90 \mathrm{~mL}$ de água estéril, sendo esta a primeira diluição, a qual foi agitada manualmente, sendo espalhadas $10 \mu \mathrm{L}, 50 \mu \mathrm{L}$, e $100 \mu \mathrm{L}$ da diluição em placas de Petri contendo meio de Martin (5 g de peptona; $0,5 \mathrm{~g}$ de $\mathrm{MgSO}_{4} .7 \mathrm{H}_{2} \mathrm{O} ; 1 \mathrm{~g}$ de $\mathrm{K}_{2} \mathrm{HPO}_{4} ; 10$ $\mathrm{mL}$ de solução de rosa bengala na concentração de $1: 300 ; 30 \mathrm{mg}$ de sulfato de estreptomicina; $10 \mathrm{~g}$ de dextrose; $20 \mathrm{~g}$ de agar-agar; 1000 $\mathrm{mL}$ de água ultrapurificada). De cada diluição, foram inoculadas três placas, que foram incubadas em câmara B.O.D a $24 \pm 2{ }^{\circ} \mathrm{C}$, fotoperíodo de $12 \mathrm{~h}$, até a formação de colônias.

Três amostras de areia foram coletadas, em diferentes canaletões. $\mathrm{O}$ isolamento da areia foi feito por meio da diluição em série, utilizando os mesmos procedimentos descritos para a diluição do substrato, sendo novamente espalhados $10 \mu \mathrm{L}, 50 \mu \mathrm{L}$, e $100 \mu \mathrm{L}$ da diluição em placas de Petri contendo meio de Martin. As placas foram incubadas conforme descrito para o isolamento de fungos do substrato.

Três amostras de brita foram coletadas no piso da casa de vegetação, ao redor de bandejas que apresentavam miniestacas com sintomas de podridão basal ou mediana. Foi utilizada a metodologia de isolamento utilizada por Duin et al. (8), na qual foram pesadas $10 \mathrm{~g}$ de cada amostra, lavadas em $90 \mathrm{~mL}$ de água esterilizada. A partir da solução da lavagem, foram coletadas, com micropipeta, alíquotas de $10 \mu \mathrm{L}, 50 \mu \mathrm{L}$, e $100 \mu \mathrm{L}$ da solução e espalhadas em placas de Petri contendo meio de Martin. Cada diluição teve três repetições, sendo as placas incubadas conforme descrito para o isolamento de fungos provenientes do substrato.

Além da diluição em série para substrato e areia, e suspensão de brita, realizou-se também teste de isca com folhas jovens de mamona (Ricinus communis L.). O teste foi instalado em caixas gerbox, com duas folhas de papel mata-borrão esterilizadas em autoclave e umedecidas com água ultrapurificada estéril e uma folha jovem de mamona. Os substratos, areia e brita, foram umedecidos com água ultrapurificada estéril e colocados sobre as folhas, sendo estas perfuradas para a liberação de enzimas estimulantes aos fungos (1). O material permaneceu em câmara úmida sob luz fria contínua e temperatura ambiente por sete dias.

Tabela 1. Fungos associados com a mortalidade de miniestacas de três clones de Eucalyptus benthamii (B1, B2 e B3) em duas épocas de coleta (setembro/2016 e abril/2017) obtidos em câmara úmida e isolamento em meio de cultura.

\begin{tabular}{|c|c|c|c|c|c|c|c|c|c|c|c|c|c|c|}
\hline \multirow{2}{*}{ Fungo } & \multicolumn{7}{|c|}{ Setembro/2016 } & \multicolumn{7}{|c|}{ Abril/2017 } \\
\hline & B1 & B2 & B3 & B1 & B2 & B3 & Média (\%) & B1 & B2 & B3 & B1 & B2 & B3 & Média (\%) \\
\hline Botrytis cinerea & - & - & - & 7 & - & - & 2,3 & - & - & - & - & - & - & - \\
\hline Cladosporium sp. & $\mathrm{X}$ & $\mathrm{X}$ & $\mathrm{X}$ & - & - & - & - & $\mathrm{X}$ & $\mathrm{X}$ & $\mathrm{X}$ & - & 3 & - & 1,0 \\
\hline Complexo Cs & $\mathrm{X}$ & $\mathrm{X}$ & $\mathrm{X}$ & - & - & - & - & $\mathrm{X}$ & $\mathrm{X}$ & $\mathrm{X}$ & 45 & 33 & 77 & 51,7 \\
\hline Calonectria sp. & - & - & - & - & - & - & - & - & $\mathrm{X}$ & - & - & - & - & - \\
\hline Dendryphiopsis sp. & - & - & - & - & 2 & 2 & 1,3 & - & - & - & - & - & - & - \\
\hline Fusarium sp. & $X$ & $\mathrm{X}$ & $\mathrm{X}$ & 11 & 6 & 10 & 9,0 & - & - & - & 9 & 17 & 8 & 11,3 \\
\hline Phomopsis sp. & - & - & - & - & - & - & - & $\mathrm{X}$ & $\mathrm{X}$ & $\mathrm{X}$ & - & - & - & - \\
\hline Trichoderma sp. & - & - & - & 13 & 5 & 14 & 10,6 & - & - & - & 12 & 10 & 4 & 8,7 \\
\hline Verticillium sp. & $\mathrm{X}$ & $\mathrm{X}$ & $\mathrm{X}$ & 5 & 1 & 1 & 2,3 & $\mathrm{X}$ & $\mathrm{X}$ & $\mathrm{X}$ & 7 & 3 & - & 3,3 \\
\hline
\end{tabular}

$\mathrm{X}=$ presente, $-=$ ausente 
Após a formação das colônias e formação de estruturas reprodutivas, fez-se a identificação dos fungos como mencionado anteriormente.

\section{RESULTADOS E DISCUSSÃO}

\section{Fungos presentes em miniestacas de $E$. benthamii}

Na primeira coleta (setembro/2016), foram encontrados oito gêneros de fungos através do isolamento indireto: Botrytis, Colletotrichum, Dendryphiopsis, Fusarium, Gliocladium, Pestalotiopsis, Trichoderma e Verticillium (Tabela 1). Pestalotiopsis sp. foi o fungo de maior incidência média (61\%), para todos os clones, seguido por Trichoderma sp. (10,6\%), Fusarium sp. (9\%), Gliocladium sp. (8\%) e Colletotrichum sp. $(5,3 \%)$. Botrytis cinerea foi encontrado apenas no clone B1. Através do isolamento direto, foram identificados sete gêneros de fungos: Cladosporium, Colletotrichum, Calonectria, Fusarium, Gliocladium, Pestalotiopsis e Verticillium (Tabela 1).

$\mathrm{Na}$ segunda coleta (abril/2017), também foram isolados oito gêneros de fungos através do isolamento indireto: Cladosporium, Colletotrichum, Complexo Cs, Fusarium, Gliocladium, Pestalotiopsis, Trichoderma e Verticillium (Tabela 1). Complexo Cs apresentou maior incidência média $(51,7 \%)$ para todos os clones estudados, seguido por Pestalotiopsis sp. (19,3\%), Fusarium sp. (11,3\%), Trichoderma sp. $(8,7 \%)$ e Gliocladium sp. (4,3\%). Através do isolamento direto, novamente, foram identificados sete gêneros de fungos: Cladosporium, Colletotrichum, Complexo Cs, Gliocladium, Pestalotiopsis, Phomopsis e Verticillium (Tabela 1). Ainda no isolamento direto sobre as miniestacas doentes, foram verificados peritécios de Calonectria sp.

Dos fungos encontrados são considerados patógenos e possíveis causadores da mortalidade de miniestacas de E. benthamii: $B$. cinerea, Colletotrichum sp., Complexo Cs, Fusarium sp. e Pestalotiopsis sp. $(2,4,16)$. Esses autores citam ainda Rhizoctonia solani Kuhn, como causador da mortalidade de miniestacas de Eucalyptus sp., porém o mesmo não foi encontrado nos isolamentos.

Schultz (17) encontrou $B$. cinerea causando podridão de miniestacas em viveiros de $E$. benthamii. Este patógeno foi constatado apenas no clone B1 e em baixa frequência (7\%). Tal fato pode ser decorrente da aplicação de produtos de biocontrole com Trichoderma sp. e Gliocladium sp. no viveiro, levando à redução da população do patógeno. Trichoderma sp. e Gliocladium sp. foram isolados e podem ser provenientes do produto aplicado.

Pestalotiopsis sp. encontrado em alta frequência nos isolamentos também foi relatado por Schultz (17) em associação com o anelamento da haste de mudas e manchas foliares em mudas de E. benthamii. Pestalotiopsis sp. também foi associado ao anelamento da haste de estacas e miniestacas em outras espécies de eucalipto, relatado como patógeno secundário ou fraco, pois sempre se encontra associado a hospedeiros debilitados ou que contenham injúrias causadas no preparo das estacas e miniestacas (2). Ainda como patógeno secundário para a podridão de miniestacas de Eucalyptus spp., há relatos da presença de Botryosphaeria ribis (4).

Não foram encontrados relatos de Fusarium sp. associado com a morte de miniestacas em eucalipto, somente para macroestacas (7). Santos et al. (16) relataram a presença de Fusarium sp. relacionado à podridão de raízes, bem como Phytophthora sp. e Pythium sp. Auer \& Santos (3) relataram a ocorrência de Fusarium spp. associados à morte de macroestacas de erva-mate, bem como Colletotrichum sp.

Com relação às épocas de coleta, final de inverno (setembro/2016)

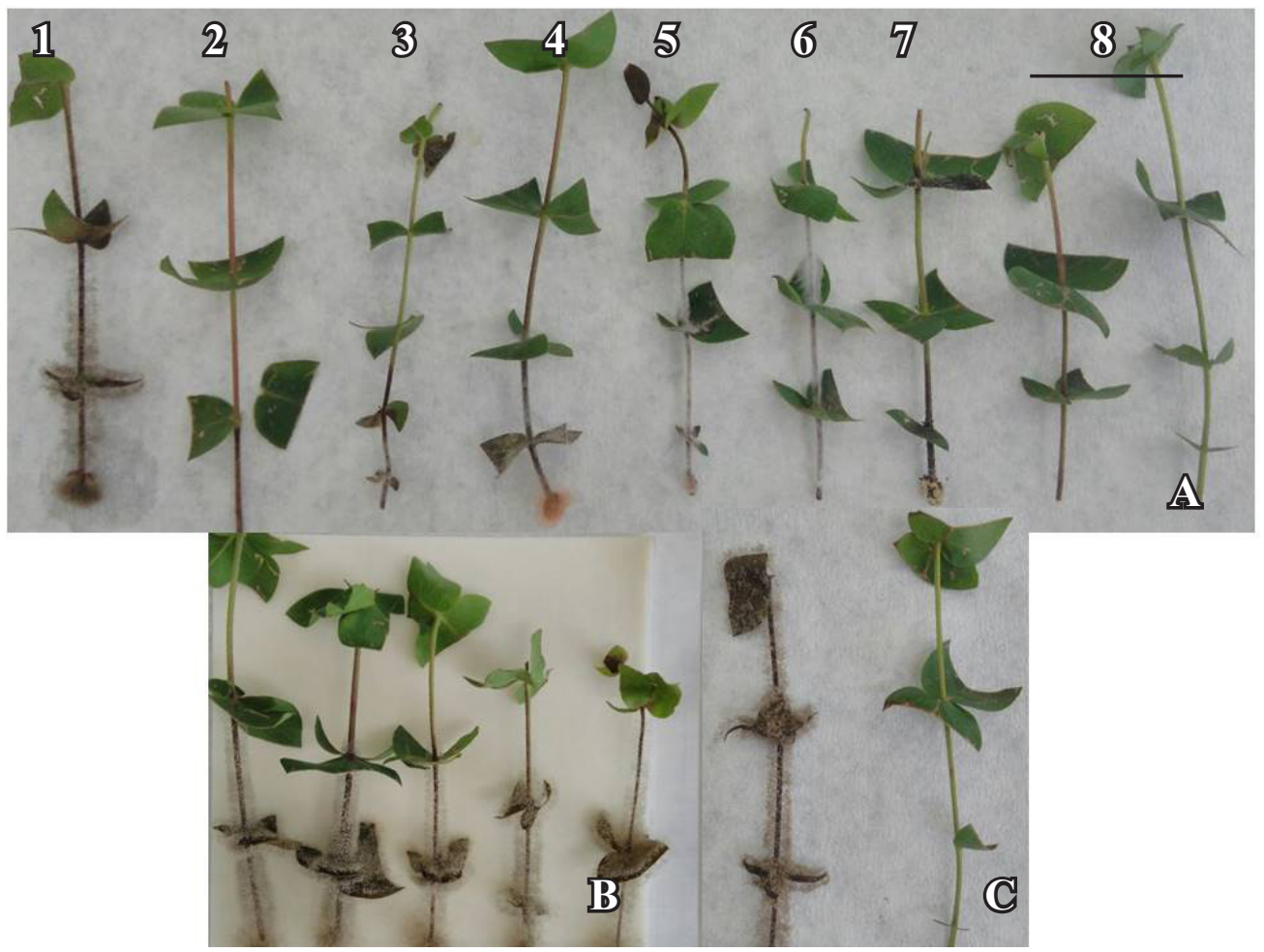

Figura 2. Patogenicidade dos fungos em miniestacas de Eucalyptus benthamii. A: Miniestacas após sete dias de inoculação - 1. Botrytis cinerea, 2. isolado 1 Complexo Cs, 3. isolado 2 Complexo Cs, 4. isolado 3 Complexo Cs, 5. isolado 1 Fusarium sp., 6. isolado 2 Fusarium sp., 7. Pestalotiopsis sp., 8. Testemunha (não inoculada); B: Miniestacas inoculadas com Botrytis cinerea após sete dias; C: Comparação de miniestaca inoculada com Botrytis cinerea e testemunha após 14 dias de inoculação. 
e final de verão (abril/2017), houve resposta diferenciada em relação à frequência e ocorrência dos fungos. Botrytis cinerea foi constatado apenas na coleta do final de inverno e em apenas um clone, resultado diverso do relatado por Cabel (6) que não correlacionou a incidência de mofo cinzento em miniestacas de Eucalyptus saligna Smith e Eucalyptus urophylla S. T. Blake x Eucalyptus globulus La Bill. e as condições ambientais ao longo do ano. Pestalotiopsis sp. foi encontrado nas duas épocas, em todos os clones com maior frequência na coleta do final de inverno. Fusarium sp., também foi encontrado nas duas épocas e em todos os clones, com frequências similares em ambas as épocas. Porém, na câmara úmida, Fusarium sp. não foi detectado na coleta do final do verão.

No caso dos isolados do Complexo Cs, valores altos de frequência foram constatados na coleta do final do verão (isolamento indireto), enquanto que no isolamento direto (câmara úmida) foram verificados em ambas as coletas. Tais diferenças podem ser explicadas pela presença de maior temperatura e umidade em abril/2017 (pós-verão), condições favoráveis para a infecção e colonização de estacas de eucalipto por Calonectria/Cylindrocladium (2), confirmadas pelo isolamento indireto. No entanto, a detecção de Calonectria pelo método direto, nas duas épocas, estaria revelando um caráter epifítico do fungo, a exemplo de Calonectria polizzii L. Lombard, Crous \& M.J. Wingf. em brotações para produção de miniestacas de acácia negra (8). Nesse caso, brotações assintomáticas mantidas por 15 dias em câmara úmida, produziram lesões escuras e frutificações de C. polizzii.

\section{Patogenicidade de fungos em miniestacas de $E$. benthamii}

Após sete dias de inoculação, todas as miniestacas apresentavam lesões que haviam progredido para podridão, e assim os isolados testados foram considerados patogênicos (Figura 2A e 2B). Após 14 dias de incubação, as miniestacas inoculadas com o isolado de $B$. cinerea apresentaram lesão em todo o seu comprimento (Figura 2C). As miniestacas que foram inoculadas com o isolado 2 Complexo Cs, os isolados 1 e 2 de Fusarium sp. e Pestalotiopsis sp. apresentaram lesão em mais de $50 \%$ de seu comprimento, confirmando as informações de Alfenas et al. (2), Auer et al. (4), que citaram espécies do gênero
Calonectria e B. cinerea como causadores da podridão de miniestacas de eucalipto. Carvalho et al. (7), também, comprovaram a patogenicidade de espécies do gênero Cylindrocladium em macroestacas de eucalipto, bem como a patogenicidade de Fusarium spp.

Com relação ao tamanho das lesões, houve diferença significativa entre clones e entre os isolados (Tabela 2). De modo geral, os clones B1 e B2 foram os mais suscetíveis aos fungos testados. No geral, tanto após sete dias ou 14 dias, os clones foram mais suscetíveis ao ataque de B. cinerea do que os demais isolados. Pestalotiopsis sp. é considerado patógeno secundário ou fraco, sendo encontrado associado a manchas foliares e anelamento da haste $(2,17)$, mas deve-se dar atenção especial a este fungo, pois o mesmo apresentou lesões médias maiores ou próximas das provocadas pelos isolados Complexo Cs (Tabela 2). Os isolados inoculados foram recuperados após o reisolamento, em frequências que variaram de 73,3 a 96,7\% (Tabela 3).

Com o teste de patogenicidade foi possível constatar diferenças quanto à agressividade dos patógenos. Resultado similar foi relatado por Paradela et al. (14) com macroestacas do híbrido Eucalyptus grandis Hill ex Maiden x Eucalyptus urophylla S. T. Blake, onde foram inoculados Botryosphaeria sp., Colletotrichum sp. e Cylindrocladium sp.

\section{Fonte de inóculo}

Nas miniestacas assintomáticas foram isolados oito gêneros fúngicos (Tabela 4), sendo quatro considerados causadores da podridão de miniestacas: Colletotrichum, Complexo Cs, Fusarium e Pestalotiopsis. Após sete dias em câmara úmida, todas as estacas apresentavam algum fungo. Em todas as estacas com lesões escuras foi verificada a presença de Pestalotiopsis sp. Paradela et al. (14), ao realizarem isolamentos patógenos de estacas assintomáticas do híbrido E. grandis x E. urophylla, também obtiveram isolados de Colletotrichum sp., Cylindrocladium sp. e Fusarium sp. Duin et al. (8) relataram a presença de Colletotrichum sp., C. polizzii, Fusarium sp. e Pestalotiopsis sp. ao isolar microrganismos de miniestacas assintomáticas de acácia-negra.

Com relação aos tubetes usados e lavados (Tabela 4), foram

Tabela 2. Tamanho médio ( $\mathrm{mm}$ ) da lesão em miniestacas de Eucalytpus benthamii inoculadas com Botrytis cinerea, Complexo Calonectria scoparia (Complexo Cs) e Fusarium spp., após sete e 14 dias de incubação.

\begin{tabular}{|c|c|c|c|c|c|c|c|}
\hline \multirow[b]{3}{*}{ Clone } & \multicolumn{7}{|c|}{ Avaliação (sete dias) } \\
\hline & \multirow{2}{*}{ Botrytis cinerea } & \multicolumn{3}{|c|}{ Complexo Cs } & \multicolumn{2}{|c|}{ Fusarium sp. } & \multirow{2}{*}{ Pestalotiopsis sp. } \\
\hline & & Isolado 1 & Isolado 2 & Isolado 3 & Isolado 1 & Isolado 2 & \\
\hline B1 & $49,8 \mathrm{a}^{*}$ & $15,4 \mathrm{ab}$ & $22,6 \mathrm{a}$ & $24,4 \mathrm{a}$ & $21,2 \mathrm{a}$ & $23,1 \mathrm{a}$ & $18,2 \mathrm{a}$ \\
\hline B2 & $52,5 \mathrm{a}$ & $16,9 \mathrm{a}$ & $24,7 \mathrm{a}$ & $15,2 \mathrm{~b}$ & $18,8 \mathrm{a}$ & $24,3 \mathrm{a}$ & $28,9 \mathrm{a}$ \\
\hline B3 & $29,4 \mathrm{~b}$ & $12,2 \mathrm{~b}$ & $16,6 \mathrm{~b}$ & $13,9 \mathrm{~b}$ & $9,2 \mathrm{~b}$ & $15,5 \mathrm{a}$ & $25,3 \mathrm{a}$ \\
\hline CV (\%) & & & & 42,4 & & & \\
\hline \multirow{2}{*}{ Clone } & \multicolumn{7}{|c|}{ Avaliação (quatorze dias) } \\
\hline & Lesão (mm) & Lesão (mm) & Lesão (mm) & Lesão $(\mathrm{mm})$ & Lesão (mm) & Lesão (mm) & Lesão (mm) \\
\hline B1 & $77,9 \mathrm{a}$ & $31,9 \mathrm{a}$ & $40,9 \mathrm{a}$ & $44,2 \mathrm{a}$ & $42,3 \mathrm{a}$ & $40,6 \mathrm{a}$ & $47,2 \mathrm{a}$ \\
\hline B2 & $78,5 \mathrm{a}$ & $32,7 \mathrm{a}$ & $51,1 \mathrm{a}$ & $43,9 \mathrm{a}$ & $44,2 \mathrm{a}$ & $47,6 \mathrm{a}$ & $40,5 \mathrm{ab}$ \\
\hline
\end{tabular}


Tabela 3. Reisolamento dos fungos após o teste de patogenicidade em miniestacas de Eucalyptus benthamii.

\begin{tabular}{ccc}
\hline \multicolumn{2}{c}{ Fungo } & Reisolamento (\%) \\
\hline Botrytis cinerea & & 73,3 \\
\hline \multirow{2}{*}{ Complexo Cs } & Isolado 1 & 80,0 \\
& Isolado 2 & 86,7 \\
& Isolado 3 & 80,0 \\
\hline \multirow{2}{*}{ Fusarium sp. } & Isolado 1 & 90,0 \\
& Isolado 2 & 96,7 \\
\hline Pestalotiopsis $\mathrm{sp}$. & & 86,7 \\
\hline
\end{tabular}

encontrados praticamente os mesmos fungos das miniestacas assintomáticas, indicando falhas no processo de higienização do material. Pestalotiopsis sp. isolado de miniestacas com apodrecimento também foi isolado dos tubetes. Pestalotiopsis sp. e Fusarium sp foram encontrados por Duin et al. (8) nos tubetes usados e lavados de miniestacas de acácia-negra. Desta forma, tubetes reutilizados podem ser considerados fonte de inóculo dos referidos fungos e principalmente para Calonectria em miniestacas de eucalipto (2).

No caso da brita da casa de vegetação, foram encontrados isolados Complexo Cs, Fusarium sp. e Pestalotiopsis sp. que são considerados patogênicos. Duin et al. (8) ao avaliarem o piso da casa de vegetação de um viveiro de acácia-negra, encontraram os mesmos gêneros de fungos, e comentaram o risco da disseminação de patógenos do piso da casa de vegetação para miniestacas, na mesa suspensa. No caso do viveiro de E. benthamii, as bandejas não se encontravam suspensas, mas diretamente sobre o piso da casa de vegetação, facilitando ainda mais a disseminação dos patógenos para as miniestacas. Assim, recomenda-se o tratamento das britas que compõem o piso da casa de vegetação com solução de $\mathrm{NaClO}$, bem como sua troca regular.

$\mathrm{Na}$ areia dos canaletões, foram encontrados Fusarium sp. e Pestalotiopsis sp. diferente do que relataram Duin et al. (8), onde não foram detectados organismos fitopatogênicos em minijardins clonais de acácia-negra. A presença desses fungos pode ser devida à ausência de quebra-vento ao redor do viveiro e a sua proximidade com áreas de cultivos agrícolas. Reis \& Santos (15) ao testarem a armadilha tipo cata-vento para verificar a presença de esporos de Helmintosporium sativum Pammel, King e Bakke no ar concluíram que havia transporte de propágulos do fungo pelo vento. Desta forma a proximidade do viveiro com áreas de cultivos agrícolas e a falta de quebra-vento podem estar associados à presença de Fusarium sp. e Pestalotiopsis sp. na areia. Uma recomendação de controle é a troca da areia durante a substituição das matrizes do minijardim.

Com relação ao substrato novo não foram encontrados fungos considerados fitopatogênicos, demonstrando sua qualidade sanitária e reduzindo a possibilidade de servir como fonte de inóculo. No substrato usado, foram encontrados Complexo Cs, Fusarium sp. e Pestalotiopsis sp. não recomendando seu reuso pelo risco de infestação dos tubetes, casa de vegetação e miniestacas sadias, aspecto ressaltado por Alfenas et al. (2) no caso de miniestacas de eucalipto.

Utilizando isca de folha de mamona, foram encontrados Complexo Cs, Cladosporium sp., Fusarium sp. e Pestalotiopsis sp. na areia, brita e substrato usado. Alfenas et al. (1), indicaram a utilização da isca de folha de mamona para verificar a presença de fungos do gênero Calonectria em substrato, porém a mesma pode ser utilizada para indicar a presença de outros fitopatógenos e em diferentes materiais, como brita e areia.

Conclui-se que os fungos B. cinerea, Complexo Cs, Fusarium spp. e Pestalotiopsis sp. são os principais agentes causais da podridão de miniestacas de E. benthamii. Miniestacas assintomáticas, tubetes usados, brita, areia e substrato usado podem ser as principais fontes de inóculo dos patógenos causadores da podridão de miniestacas.

\section{AGRADECIMENTOS}

Agradecemos à Golden Tree Reflorestadora pela cessão de material para a realização do trabalho, à CAPES pela bolsa do primeiro autor, à Embrapa Florestas pelo apoio estrutural e técnico e à Profa. Maria Alves Ferrreira pela identificação molecular dos isolados de Calonectria.

Tabela 4. Fungos encontrados em diferentes materiais coletados no viveiro clonal com mortalidade de miniestacas de Eucalyptus benthamii.

\begin{tabular}{|c|c|c|c|c|c|c|}
\hline \multirow{2}{*}{ Fungo } & \multicolumn{5}{|c|}{ Fonte de inóculo } & \multirow[b]{2}{*}{ Substrato novo } \\
\hline & Miniestaca assintomática & Tubete & Brita & Areia & Substrato usado & \\
\hline Aspergillus sp. & - & + & - & - & + & + \\
\hline Chaetomium sp. & - & + & - & - & - & - \\
\hline Cladosporium sp. & + & + & - & + & - & - \\
\hline Colletotrichum sp. & + & - & - & - & - & - \\
\hline Complexo Cs & + & - & + & - & + & - \\
\hline Fusarium sp. & + & - & + & + & + & - \\
\hline Gliocladium sp. & + & + & - & - & + & + \\
\hline Penicillium sp. & - & + & - & + & + & + \\
\hline Pestalotiopsis sp. & + & + & + & + & + & - \\
\hline Phomopsis sp. & + & - & - & - & - & - \\
\hline Trichoderma sp. & - & + & + & + & + & + \\
\hline Verticillium sp. & + & + & - & - & + & + \\
\hline Xylaria sp. & - & + & - & - & - & - \\
\hline
\end{tabular}

(+) presente; (-) ausente 


\section{REFERÊNCIAS}

1. Alfenas, A.C.; Ferreira, F.A.; Mafia, R.G.; Gonçalves, R.C. Isolamento de fungos fitopatogênicos. In: Alfenas, A.C.; Mafia, R.G. Métodos em Fitopatologia. 2.ed. Viçosa, MG: Editora UFV, 2016. p.55-93.

2. Alfenas, A.C.; Zauza, E.A.V.; Mafia, R.G.; Assis, T.F. Clonagem e doenças do eucalipto. 2.ed. Viçosa: Editora UFV, 2009. 500p.

3. Auer, C.G.; Santos, A.F. Doenças da erva-mate. In: Amorim, L.; Rezende, J.A.M.; Bergamin Filho, A.; Camargo, L.E.A. (Org.). Manual de fitopatologia. 5.ed. Ouro Fino: Agronômica Ceres, 2016. v.2, p.343-349.

4. Auer, C.G.; Santos, A.F.; Furtado, E.L. Doenças do eucalipto. In: Amorim, L.; Rezende, J.A.M.; Bergamin Filho, A.; Camargo, L.E.A. (Org.). Manual de fitopatologia. 5.ed. Ouro Fino: Agronômica Ceres, 2016. v.2, p.359-372.

5. Barnett, H.L.; Hunter, B.B. Illustrated genera of imperfect fungi. 3.ed. New York: MacMillan, 1972. 241p.

6. Cabel, S.R. Relações entre condições meteorológicas com a miniestaquia e a incidência de doenças bióticas em viveiro clonal de eucalipto no sul do Brasil. 2014. 73 p. Tese (Doutorado em Engenharia Florestal) -Universidade Federal do Paraná, Curitiba.

7. Carvalho, A.O.; Alfenas, A.C.; Demuner, N.L. Patogenicidade de fungos isolados de estacas de eucalipto para enraizamento, em casa de vegetação. Fitopatologia Brasileira, Brasília, DF, v.14, n.2, p.122, 1989. (Resumo 55).

8. Duin, I.M.; Higa, A.R.; Santos, A.F.; Coelho, T.A.V.; Rezende, E.H.; Auer, C.G. Etiologia e possíveis fontes de inóculo para a ocorrência da podridão de miniestacas de acácia-negra. Summa Phytopathologica, Botucatu, v.43, n.4, p.297-302, 2017.

9. Higa, R.C.V.; Pereira, J.C.D. Usos potenciais do Eucalyptus benthamii Maiden et Cambage. Colombo, PR: Embrapa Florestas, 2003. 4p. (Comunicado Técnico, 100).
10. Mafia, R.G.; Alfenas, A.C. Preparações e observações microscópicas de espécimes fúngicos. In: Alfenas, A.C.; Mafia, R.G. Métodos em fitopatologia. 2.ed. Viçosa, MG: Editora UFV, 2016. p.207-224.

11. Mello, S.C.M.; Reis, A.; Silva, J.B.T. Manual de curadores de germoplasma: micro-organismos: fungos filamentosos. Brasília, DF: Embrapa Recursos Genéticos e Biotecnologia, 2011.25p.

12. Mora, A.L.; Garcia, C.H. A cultura do eucalipto no Brasil. São Paulo: Sociedade Brasileira de Silvicultura, 2000. 112p.

13. Paludzyszyn Filho, E.; Santos, P.E.T.; Ferreira, C.A. Eucaliptos indicados para plantio no estado do Paraná. Colombo: Embrapa Florestas, 2006. 45p. (Embrapa Florestas Documentos, 129).

14. Paradela, A.L.; Bedendo, I.P.; Krugner, T.L. Comunidade fúngica associada a brotações de Eucalyptus em jardim clonal e seu envolvimento na etiologia da podridão de estacas utilizadas para produção de mudas. Summa Phytopathologica, Jaguariúna, v.25, n.2, p.144-151, 1999.

15. Reis, E.M.; Santos, H.P. dos. População de Helmintosporium sativum no ar quantificado através de uma armadilha tipo cata-vento. Fitopatologia Brasileira, Brasília, DF, v.10, p.515-519, 1985.

16. Santos, A.F.; Auer, C.G.; Grigoletti Júnior, A. Doenças do eucalipto no sul do Brasil: identificação e controle. Colombo: Embrapa Florestas, 2001 20p. (Circular Técnica, 45).

17. Schultz, B. Levantamento de doenças bióticas e abióticas em Eucalyptus benthamii Maiden nos Estados do Paraná e Santa Catarina. 2011. 101p. Dissertação (Mestrado em Engenharia Florestal) -Universidade Federal do Paraná, Curitiba.

18. Silva, F.A.S.; Azevedo, C.A.V. The Assistat Software Version 7.7 and its use in the analysis of experimental data. African Journal of Agricultural Research, Nairobi, v.11, n.39, p.3733-3740, 2016. 